\title{
Improved skin permeation of methotrexate via nanosized ultradeformable liposomes
}

\author{
This article was published in the following Dove Press journal: \\ International Journal of Nanomedicine \\ 8 August 2016 \\ Number of times this article has been viewed
}

\author{
Alam Zeb \\ Omer Salman Qureshi \\ Hyung-Seo Kim \\ Ji-Hye Cha \\ Hoo-Seong Kim \\ Jin-Ki Kim \\ College of Pharmacy, Institute \\ of Pharmaceutical Science and \\ Technology, Hanyang University, \\ Ansan, Gyeonggi, Republic of Korea
}

Correspondence: Jin-Ki Kim College of Pharmacy, Institute of Pharmaceutical Science and Technology, Hanyang University, 55 Hanyangdaehak-ro, Sangnok-gu, Ansan, Gyeonggi 426-79I, Republic of Korea $\mathrm{Tel}+82314005808$

Fax +82314005958

Email jinkikim@hanyang.ac.kr
Abstract: The aim of this study is to investigate methotrexate-entrapped ultradeformable liposomes (MTX-UDLs) for potential transdermal application. MTX-UDLs were prepared by extrusion method with phosphatidylcholine as a bilayer matrix and sodium cholate or Tween 80 as an edge activator. The physicochemical properties of MTX-UDLs were determined in terms of particle size, polydispersity index, zeta potential, and entrapment efficiency. The deformability of MTX-UDLs was compared with that of methotrexate-entrapped conventional liposomes (MTXCLs) using a steel pressure filter device. The skin permeation of MTX-UDLs was investigated using Franz diffusion cell, and the skin penetration depth of rhodamine 6G-entrapped UDLs was determined by confocal laser scanning microscopy. MTX-UDLs showed a narrow size distribution, with the particle size of $\sim 100 \mathrm{~nm}$. The deformability of MTX-UDLs was two to five times greater than that of MTX-CLs. The skin permeation of MTX-UDLs was significantly improved compared with MTX-CLs and free MTX solution. The optimized UDLs (phosphatidylcholine: Tween $80=7: 3, \mathrm{w} / \mathrm{w}$ ) showed a higher fluorescence intensity than conventional liposomes at every increment of skin depth. Thus, the optimized UDLs could be promising nanocarriers for systemic delivery of MTX across skin.

Keywords: ultradeformable liposomes, deformability, methotrexate, skin permeation, transdermal delivery

\section{Introduction}

Transdermal drug delivery has been extensively studied for the past few decades as an attractive and valuable alternative for oral and parenteral administration. ${ }^{1,2}$ The major advantages of transdermal delivery are convenience, noninvasiveness, improved patient compliance, avoidance of first-pass metabolism, avoiding some serious side effects, and bypassing the variables affecting the drug absorption in the gastrointestinal tract. $^{3}$ Despite these obvious advantages of transdermal delivery, the number of drug molecules administered via this route is quite limited due to the barrier function of stratum corneum, the outermost layer of the epidermis of skin. ${ }^{4}$ Various approaches including the use of permeation enhancers, microneedles, iontophoresis, electroporation, jet injection, and nanocarriers have been applied to increase drug penetration by overcoming the barrier function of skin. ${ }^{5}$

Liposomes as nanosized carriers are promising transdermal drug delivery systems since they are biocompatible and can carry both water-soluble and lipid-soluble drugs. ${ }^{6}$ Even though conventional liposomes (CLs), typically consisting of phospholipid and cholesterol $(\mathrm{CH})$, have been investigated, their effectiveness in delivering a therapeutically significant amount of drug across skin is still a question mark. ${ }^{2}$ It was reported that liposomes with lower elastic modulus and higher deformability could be driven deep into the skin by hydration gradient when applied nonocclusively. ${ }^{7}$ Deformability was 
imparted to liposomes by incorporating surfactant known as an "edge activator" into lipid bilayers (Figure 1A). This new class of liposomes with an edge activator was termed as elastic, flexible, or ultradeformable liposomes (UDLs). The stress-dependent adaptability enables UDLs to squeeze themselves through the interstices of the stratum corneum by using transepidermal hydration gradient (Figure 1B), thus passing through the skin without disruption of vesicular structure. ${ }^{8}$ UDLs showed better in vitro and in vivo skin permeation than CLs when applied for diclofenac, ketotifen, triamcinolone acetonide, dexamethasone, hydrocortisone, estradiol, 5-fluorouracil, and insulin. ${ }^{9-15}$

Methotrexate (MTX) is a folate receptor antagonist that was originally developed as a chemotherapeutic agent to treat various kinds of malignancies, including leukemia, breast cancer, lung cancer, head and neck cancer, osteosarcoma, and non-Hodgkin's lymphoma. ${ }^{16,17}$ It has also been reported that low doses of MTX are effective to treat some inflammatory and autoimmune conditions such as rheumatoid arthritis and psoriasis. ${ }^{18}$ Oral and parenteral administration of MTX is associated with serious side effects, including gastrointestinal and hepatic toxicity. ${ }^{19}$ Additionally, the first-pass metabolism with oral administration of MTX significantly reduces its bioavailability. ${ }^{20}$ Transdermal delivery of MTX can not only avoid the drawbacks of oral and parenteral formulations but also improve the therapeutic efficacy of MTX. ${ }^{21}$ However, the high polarity $(\log P=-1.85)$ and ionized form of MTX at physiologic $\mathrm{pH}$ make it challenging to be delivered transdermally via the lipophilic stratum corneum. ${ }^{19}$ For transdermal delivery of MTX, various kinds of nanocarriers such as nanostructured lipid carriers, ${ }^{21,22}$ magnetic silk fibroin nanoparticles, ${ }^{23}$ liposomes,${ }^{24}$ ethosomes, ${ }^{20}$ solid-in-oil nanocarriers, ${ }^{19}$ and nanogels ${ }^{25,26}$ have been investigated.
Considering the water solubility of MTX and the deformability of UDLs with aqueous phase, UDLs could be a promising nanocarrier for efficient transdermal delivery of MTX.

This study aimed to investigate the skin permeation potential of methotrexate-entrapped ultradeformable liposomes (MTX-UDLs) for transdermal delivery. MTX-UDLs were prepared by extrusion method using sodium cholate (SC) or Tween 80 (TW80) as an edge activator. MTX-UDLs with different ratios of lipid (L- $\alpha$-phosphatidylcholine [PC]) to edge activator were prepared, and their physicochemical properties were characterized in terms of size, polydispersity index (PDI), zeta potential, and entrapment efficiency. The effect of different types and ratios of edge activators on the deformability of MTX-UDLs was evaluated and compared with methotrexate-entrapped conventional liposomes (MTX-CLs). The optimized MTX-UDLs formulations were then investigated for skin permeation by using Franz diffusion cell and confocal laser scanning microscopy (CLSM).

\section{Materials and methods \\ Materials}

MTX was kindly gifted by Huzhou Zhanwang Pharmaceutical Co., Ltd (Zhejiang, People's Republic of China). PC was purchased from Avanti Polar Lipids Inc. (Alabaster, AL, USA). CH, SC, TW80, and Triton X-100 were purchased from Sigma-Aldrich Co. (St Louis, MO, USA). All other chemicals were of analytical grade and were used without any further purification.

\section{Preparation of MTX-UDLs}

MTX-UDLs were prepared by the extrusion method with slight modifications. ${ }^{27}$ Briefly, the mixture of a bilayer matrix (PC) and an edge activator (SC or TW80) was dissolved
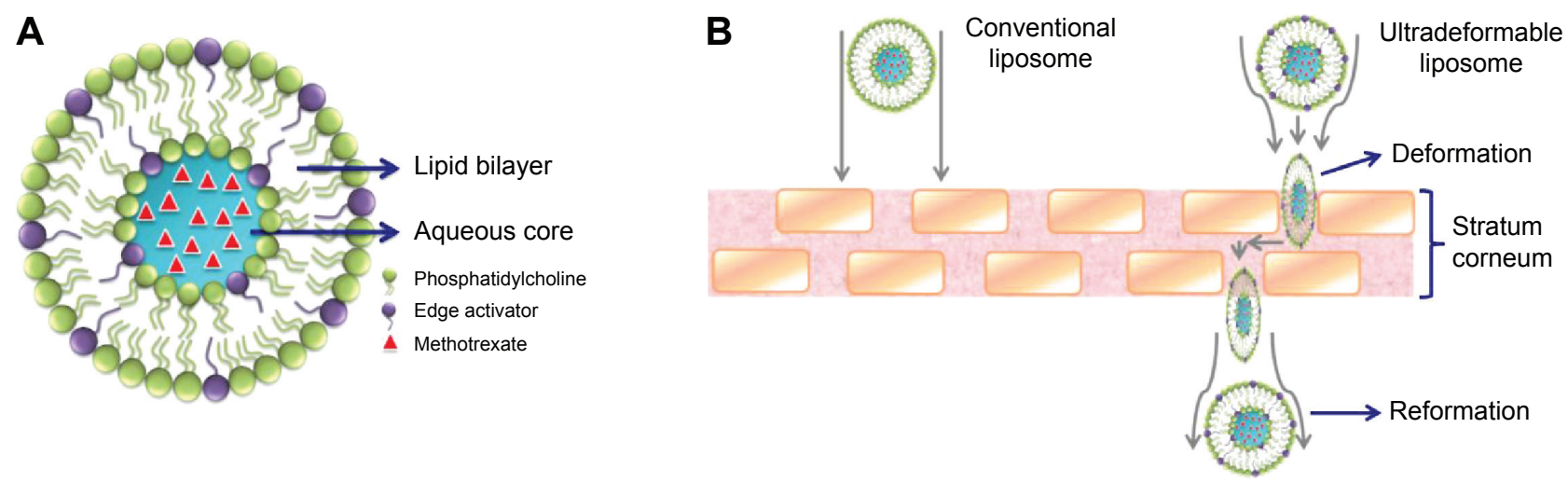

Figure I Diagrammatic illustration of MTX-UDLs (A) and mechanism of MTX-UDLs transport in skin permeation (B). Note: During skin permeation, the vesicular structure of UDLs is maintained via deformation and reformation. Abbreviation: MTX-UDLs, methotrexate-entrapped ultradeformable liposomes. 
in $1 \mathrm{~mL}$ of chloroform/methanol $(2 / 1, \mathrm{v} / \mathrm{v})$. The organic solvent was removed by rotary evaporator (Rotavapor R-3; Büchi Labortechnik AG, Flawil, Switzerland) under reduced pressure at $40^{\circ} \mathrm{C}$ to form a thin lipid film. The thin film was further dried by using a stream of nitrogen gas for 30 minutes to remove the traces of organic solvent. The dried film was hydrated with the solution of MTX in phosphate-buffered saline (PBS) ( $\mathrm{pH}$ 7.4). The hydration medium was preheated at $65^{\circ} \mathrm{C}$, which is above the phase transition temperature $\left(T_{\mathrm{m}}\right)$ of PC. The hydrated suspension was sonicated in a bath type sonicator at $65^{\circ} \mathrm{C}$ for 30 minutes and extruded 20 times through $100 \mathrm{~nm}$ polycarbonate membrane by using a Mini-Extruder (Avanti Polar Lipids, Inc.). MTX-CLs were prepared by the same method except that $\mathrm{CH}$ was used instead of edge activator (SC or TW80). The prepared MTX-UDLs and MTX-CLs were stored at $4^{\circ} \mathrm{C}$ for further analysis. The composition of MTX-UDLs and MTX-CLs with different ratios of $\mathrm{PC}$ and $\mathrm{SC} / \mathrm{TW} 80 / \mathrm{CH}$ is presented in Table 1.

\section{Physicochemical characterization of MTX-UDLs}

The physicochemical properties of MTX-UDLs were characterized in terms of particle size, PDI, zeta potential, and entrapment efficiency. The average particle size and PDI of MTX-UDLs were determined by photon correlation spectroscopy using a Zetasizer Nano ZS (Malvern Instruments, Malvern, UK). Prior to measurement, MTX-UDLs were diluted 100 times with filtered deionized water. The zeta potential of MTX-UDLs was measured by electrophoretic light scattering using the same instrument. The entrapment efficiency of MTX-UDLs was determined by ultrafiltration centrifugation method. ${ }^{28}$ MTX-UDLs were added into Amicon Ultra- 0.5 centrifugal filter units (Amicon Ultracel-10k; EMD Millipore, Billerica, MA, USA) and centrifuged at $14,000 \times g$ for 30 minutes. The separated vesicles were disrupted by $0.2 \%$ Triton X-100 in PBS (pH 7.4). The resultant solution was then analyzed for MTX contents by using UV-visible spectrophotometer (Ultrospec 7000; Biochrom Ltd, Cambridge, UK) at

Table I Composition of MTX-UDLs and MTX-CLs in weight ratio

\begin{tabular}{llllll}
\hline Formulation & PC & SC & TW80 & CH & MTX \\
\hline MTX-UDLs-S2 & 8 & 2 & - & - & 1.5 \\
MTX-UDLs-S3 & 7 & 3 & - & - & 1.5 \\
MTX-UDLs-T2 & 8 & - & 2 & - & 1.5 \\
MTX-UDLs-T3 & 7 & - & 3 & - & 1.5 \\
MTX-CLs & 8 & - & - & 2 & 1.5 \\
\hline
\end{tabular}

Abbreviations: MTX, methotrexate; UDLs, ultradeformable liposomes; CLs, conventional liposomes; PC, phosphatidylcholine; SC, sodium cholate; TW80, Tween 80; $\mathrm{CH}$, cholesterol.
$303 \mathrm{~nm}$. The entrapment efficiency (\%) was calculated by using the following equation:

$$
\begin{aligned}
& \text { Entrapment efficiency }(\%) \\
& \qquad=\frac{\text { Amount of MTX entrapped in UDLs }}{\text { Total amount of MTX added }} \times 100
\end{aligned}
$$

\section{Transmission electron microscopy}

The morphology of MTX-UDLs was confirmed by transmission electron microscopy (TEM) (JEM-2100F; JEOL, Tokyo, Japan) using a staining method..$^{29}$ Diluted MTX-UDLs were placed on carbon-coated 400-mesh copper grid and were allowed to adsorb on to the grid. The sample was then negatively stained by adding a drop of $1 \%$ solution of phosphotungstic acid followed by drying at room temperature. Finally, MTX-UDLs were imaged with TEM operating at an accelerating voltage of $200 \mathrm{kV}$.

\section{Deformability of MTX-UDLs}

The deformability is a crucial property for an efficient skin permeation of UDLs. The deformability of MTX-UDLs was determined by using the stainless steel pressure filter device (Lipix Extruder; Northern Lipids Inc., Burnaby, BC, Canada). ${ }^{30}$ MTX-UDLs were extruded through $50 \mathrm{~nm}$ polycarbonate membranes at a constant pressure of $0.2 \mathrm{MPa}$. The rate of penetration was obtained from the volume of vesicles suspension extruded in 5 minutes. After extrusion, the average particle size of MTX-UDLs was measured by photon correlation spectroscopy using a Zetasizer Nano ZS (Malvern Instruments). The deformability index $(D)$ of MTX-UDLs was calculated by the following equation:

$$
D=J \times\left(\frac{r_{v}}{r_{p}}\right)^{2}
$$

where $D$ is the deformability of vesicles, $J$ is the rate of penetration through a permeability membrane, $r_{v}$ is the particle size after extrusion, and $r_{p}$ is the pore diameter of a permeability membrane $(50 \mathrm{~nm})$.

\section{In vitro skin permeation of MTX-UDLs Preparation of rat skin}

Full-thickness skin was obtained from the abdominal area of healthy male Sprague Dawley rats weighing $260 \pm 20 \mathrm{~g}$. The abdominal area of rats was shaved, and skin was carefully excised after sacrificing under deep isoflurane anesthesia. The underlying fats and connecting tissues of skin were carefully removed. 
Full-thickness skin was finally washed with saline and stored at $-20^{\circ} \mathrm{C} .{ }^{31}$ The skin was thawed for 30 minutes at room temperature prior to in vitro permeation study. All animal-handling procedures were performed according to the Guide for the Care and Use of Laboratory Animals of the National Institutes of Health and followed the guidelines of the Animal Welfare Act. All animal experiments were approved by the Institutional Animal Care and Use Committee of Hanyang University.

\section{Skin permeation study}

Skin permeation studies were performed using Franz diffusion cell assembly consisting of vertical diffusion cells (Model \# 58-001-802; Hanson Research Corporation, Chatsworth, CA, USA), magnetic stirring control system, and heating circulation system with a programmable temperature control device. Franz diffusion cells had an effective permeation area of $1.77 \mathrm{~cm}^{2}$ and receptor cell volume of $7 \mathrm{~mL}$. The receptor compartment was filled with $7 \mathrm{~mL}$ of PBS (pH 7.4) and constantly stirred at $500 \mathrm{rpm}$. The receptor compartment was maintained at $37^{\circ} \mathrm{C} \pm 0.5^{\circ} \mathrm{C}$ with heating circulating system. ${ }^{31}$ The full-thickness rat skin was then mounted between donor and receptor compartments. Open hydration protocol was adopted to generate a driving force for the skin permeation of UDLs known as transepidermal hydration gradient. ${ }^{7,32}$ The upper surface of mounted skin was left dry and open for 12 hours, while the dermal side of the skin was in contact with the receptor medium. The aqueous dispersion of MTX-UDLs or MTX-CLs equivalent to $1.5 \mathrm{mg}$ of MTX was loaded in the donor compartment, and $0.5 \mathrm{~mL}$ of the sample was withdrawn through the sampling port at predetermined times $(0.5$ hour, 1 hour, 2 hours, 4 hours, 8 hours, 12 hours, 16 hours, 20 hours, and 24 hours). The receptor phase was immediately replenished with an equal volume of fresh diffusion medium with the same temperature. Sink conditions were maintained throughout the experimental procedure. The collected samples were analyzed for MTX contents after suitable dilutions with PBS (pH 7.4).

\section{Calculation of skin permeation parameters}

The cumulative amount of MTX permeated per unit area was calculated by using the following equation: ${ }^{33}$

$$
Q_{\mathrm{n}}=\frac{C_{\mathrm{n}} V_{\mathrm{r}}+\sum_{i=0}^{\mathrm{n}-1} C_{i} V_{\mathrm{s}}}{A}
$$

where $Q_{\mathrm{n}}$ is the cumulative amount of drug permeated per unit area $\left(\mu \mathrm{g} / \mathrm{cm}^{2}\right)$ corresponding to the time of $\mathrm{nth}$ sample, $C_{\mathrm{n}}$ is the drug concentration in receptor fluid at the time of nth sample, $C_{i}$ is the drug concentration in receptor fluid at the time of $i$ th $(\mathrm{n}-1)$ sample, $V_{\mathrm{r}}$ is the volume of receptor solution $(7 \mathrm{~mL}), V_{\mathrm{s}}$ is the volume of sample withdrawn $(0.5 \mathrm{~mL})$, and $A$ is the effective permeation area of diffusion cell $\left(1.77 \mathrm{~cm}^{2}\right)$.

The cumulative amount of MTX permeated per unit area $\left(Q_{\mathrm{n}}\right)$ was plotted as a function of time. The steady-state flux $\left(J_{\text {ss }}\right.$ expressed as $\left.\mu \mathrm{g} / \mathrm{cm}^{2} / \mathrm{h}\right)$ and lag time $\left(\mathrm{t}_{\mathrm{lag}}\right)$ were calculated from the slope and $x$-intercept of linear portion of graph, respectively. Permeability coefficient $\left(K_{\mathrm{p}}\right)$ was calculated by dividing the steady-state flux $\left(J_{\text {ss }}\right)$ by the initial amount of MTX in donor compartment. Enhancement ratio was calculated by dividing the flux of the test formulation by that of the control formulation (MTX-CLs).

$$
\text { Enhancement ratio }=\frac{J_{\mathrm{ss}} \text { of MTX-UDLs }}{J_{\mathrm{ss}} \text { of MTX-CLs }}
$$

\section{Confocal laser scanning microscopy}

CLSM was performed to evaluate the depth of skin penetration of UDLs using rhodamine 6G (R6G) as a fluorescence marker. R6G-entrapped UDLs (R6G-UDLs), R6G-entrapped CLs (R6G-CLs), and R6G solution $(0.03 \% \mathrm{w} / \mathrm{v})$ were applied to rat skin mounted on the Franz diffusion cell for 4 hours under the same conditions as in vitro skin permeation studies. After 4 hours incubation, the excess of each formulation was wiped off with a filter paper. The skin was washed with distilled water and finally frozen at $-20^{\circ} \mathrm{C}$. The frozen skin was vertically sectioned into $5 \mu \mathrm{m}$ thick slices with a cryostat microtome. The skin sections were optically scanned at every $5 \mu \mathrm{m}$ increment though the $z$-axis to measure the depth of fluorescence marker (R6G) penetration by using CLSM (TCS SP5; Leica Microsystems, Wetzlar, Germany). The optical excitation of R6G was carried out at $550 \mathrm{~nm}$, while emission was observed at $>560 \mathrm{~nm}$. The images of skin sections $(1,024 \times 1,024 \mu \mathrm{m})$ were obtained at $10 \times$ magnification. The obtained images were then quantitatively analyzed for fluorescence intensity at various depths by using LAS AF Lite software. ${ }^{34-36}$

\section{Evaluation of skin structure after MTX-UDLs treatment}

The skin structure after MTX-UDLs treatment was investigated by differential scanning calorimetry (DSC) and attenuated total reflectance Fourier transform infrared spectroscopy (ATR-FTIR). The alteration of lipid organization in stratum corneum was analyzed since the permeation enhancers or transdermal formulations mainly induce structural changes in epidermis area, specifically stratum corneum. ${ }^{37}$ Epidermis 
from rat skin was separated by immersing in deionized water at $60^{\circ} \mathrm{C}$ for 2 minutes followed by gentle peeling off with forceps. ${ }^{38}$ The isolated epidermis was treated with the optimized MTX-UDLs (MTX-UDLs-T3) for 4 hours on Franz diffusion cell under the same conditions as in vitro skin permeation studies. The epidermis treated with MTX-UDLs was washed carefully with PBS and subjected to DSC and FTIR after blot-drying.

Thermal analysis of the epidermis was performed with a differential scanning calorimeter (DSC Q20; TA Instrument, New Castle, DE, USA). The epidermis samples weighing 5-10 $\mathrm{mg}$ were crimped in a standard aluminum pan and heated from $30^{\circ} \mathrm{C}$ to $150^{\circ} \mathrm{C}$ at $10^{\circ} \mathrm{C} / \mathrm{min}$ heating rate with $50 \mathrm{~mL} / \mathrm{min}$ nitrogen flow. The lipid organization of stratum corneum in epidermis was further studied by monitoring the molecular vibrations of lipid components from ATR-FTIR. The infrared transmission spectra were recorded using an FTIR spectrophotometer (FTIR-4100; JASCO International Co., Ltd, Tokyo, Japan). The epidermal sample of $1 \mathrm{~cm}^{2}$ was mounted on a diamond ATR crystal, and the spectra were recorded over the wave number range of $4,000-650 \mathrm{~cm}^{-1}$ at a resolution of $4 \mathrm{~cm}^{-1}$.

\section{Stability study}

The storage stability of the optimized MTX-UDLs (MTXUDLs-T3) was evaluated at $4^{\circ} \mathrm{C}$ and $25^{\circ} \mathrm{C}$ for 90 days. For the stability study, the formulation was stored in sealed glass vials flushed with nitrogen gas. Samples were collected at 0 day, 15 days, 30 days, 60 days, and 90 days and monitored for changes in particle size, PDI, zeta potential, and entrapment efficiency.

\section{Statistical analysis}

Data are expressed as the mean \pm standard deviation (SD) of three independent experiments. Student's $t$-test was applied using SPSS software (SPSS Inc., Chicago, IL, USA) to determine the statistical significant differences between groups. A value of $P<0.05$ was considered to be statistically significant.

\section{Results and discussion \\ Preparation of MTX-UDLs}

MTX-UDLs with different ratios of PC to edge activator were reproducibly prepared by extrusion method. In this study, SC and TW80 were selected as edge activators to impart deformability to the lipid vesicles. SC and TW80 are pharmaceutically acceptable and extensively investigated as edge activators for UDLs. ${ }^{32,39-41}$ Amphiphilic molecules such as bile salts ( $\mathrm{SC}$ and sodium deoxycholate), Tweens (ethoxylated sorbitan esters), and Spans (sorbitan esters) have been extensively studied to provide deformability to liposomes. ${ }^{14,32,41}$ Bile salts and Tweens were preferred over Spans since hydrophilic surfactants induce more deformability by increasing membrane fluidity and forming transient holes in lipid bilayers than lipophilic ones. ${ }^{27} \mathrm{SC}$ was selected from the bile salts due to nonsignificant difference in deformability between SC and sodium deoxycholate liposomes. ${ }^{15}$ From the results demonstrating that the unsaturated and highly flexible hydrocarbons in nonionic surfactants form more deformable membranes, TW80 was used to prepare UDLs in this study. ${ }^{27}$ The high curvature radius and mobility of edge activators enable UDLs to transform their shape and volume at lower energy. When exposed to mechanical stress or space confinement, edge activators relocate themselves in the zones of higher curvature, while phospholipids are positioned in the bilayer regions with smaller curvature. The readjustment of edge activators in UDLs was speculated to be the main reason why UDLs pass through the pores smaller than their own diameter without being disassembled. ${ }^{42,43}$ Optimal PC to edge activator ratios were selected as 8:2 and 7:3 (w/w) on the basis of particle size, PDI, entrapment efficiency, and deformability index from our preliminary studies. In the preliminary studies, MTX-UDLs with PC to edge activator ratio of 9:1 and 6:4 were also prepared and evaluated. MTX-UDLs with 9:1 (PC to edge activator ratio) showed low deformability index at 19.9 for SC and 22.3 for TW80, which were not significantly different from that of MTX-CLs. In the case of MTX-UDLs with 6:4 (PC to edge activator ratio), the entrapment efficiencies were $<20 \%$ for SC and TW80. Considering the low deformability and low entrapment efficiency, MTX-UDLs with these ratios were excluded from further studies. MTX-CLs (PC:CH =8:2) were also prepared as a control formulation for comparison. The amount of MTX was kept constant at $1.5 \mathrm{mg} / \mathrm{mL}$ in all the formulations.

\section{Physicochemical properties and morphology of MTX-UDLs}

The physicochemical properties of the optimized MTX-UDLs were evaluated in terms of particle size, PDI, zeta potential, and entrapment efficiency (Table 2). The optimized MTX-UDLs showed mean particle sizes around $100 \mathrm{~nm}$ with narrow size distribution indicated by PDI values $<0.150$. The particle size distribution curve was unimodal in shape (Figure 2A). There were no statistical significant differences $(P>0.05)$ in the particle size between UDLs containing the same $\mathrm{PC}$ to edge activator ratio. However, a slight reduction 
Table 2 Physicochemical properties of MTX-UDLs and MTX-CLs

\begin{tabular}{lllll}
\hline Formulation & Particle size $\mathbf{( n m )}$ & PDI & Zeta potential (mv) & $\begin{array}{l}\text { Entrapment } \\
\text { efficiency (\%) }\end{array}$ \\
\hline MTX-UDLs-S2 & $94.9 \pm 5.0$ & $0.114 \pm 0.054$ & $-15.7 \pm 0.8$ & $32.6 \pm 2.1$ \\
MTX-UDLs-S3 & $81.6 \pm 6.5$ & $0.124 \pm 0.052$ & $-18.0 \pm 2.6$ & $30.6 \pm 1.2$ \\
MTX-UDLs-T2 & $102.6 \pm 3.5$ & $0.101 \pm 0.020$ & $-11.7 \pm 1.2$ & $37.4 \pm 1.1$ \\
MTX-UDLs-T3 & $87.7 \pm 4.4$ & $0.048 \pm 0.009$ & $-14.7 \pm 1.9$ & $34.5 \pm 1.4$ \\
MTX-CLs & $110.8 \pm 3.9$ & $0.088 \pm 0.039$ & $-22.1 \pm 2.3$ & $28.1 \pm 1.9$ \\
\hline
\end{tabular}

Note: Data are expressed as mean \pm SD $(n=3)$.

Abbreviations: MTX, methotrexate; UDLs, ultradeformable liposomes; CLs, conventional liposomes; PDI, polydispersity index; SD, standard deviation.

in the particle size was observed on increasing the amount of edge activator (PC:edge activator ratio, 8:2 vs 7:3). The particle size of MTX-UDLs decreased from $94.9 \mathrm{~nm}$ to $81.6 \mathrm{~nm}$ and from 102.6 to $87.7 \mathrm{~nm}$ when the amount of SC and TW80 increased, respectively. The decrease in particle size resulted from the increase in the curvature of UDLs at a higher edge activator amount. ${ }^{44,45}$ The increased curvature in UDLs with smaller particle sizes is also accompanied with the reduction of aqueous phase volume for MTX entrapment. ${ }^{13}$ From the results, the reduction in MTX entrapment in UDLs was related to the increased curvature with reduced aqueous phase volume at a higher edge activator amount. The zeta potential of MTX-UDLs indicated a negatively charged surface of vesicles. The negative zeta potential of UDLs with $\mathrm{SC}$ as an edge activator is originated from the anionic nature of SC (cholate anions). Even though TW80 is a nonionic surfactant, UDLs with TW80 showed the negative value of zeta potential due to the partial hydrolysis of polyethylene oxide head groups $\left(\mathrm{CH}_{2}-\mathrm{CH}_{2}-\mathrm{O}\right)_{\mathrm{n}}$ of TW80. ${ }^{40,44,46}$ TEM image of the optimized MTX-UDLs (MTX-UDLs-T3) confirmed their vesicular morphology with spherical shape and unilamellar structure (Figure 2B). The initial large multilamellar vesicles were converted into unilamellar MTX-UDLs after extrusion process. The particle size of MTX-UDLs was consistent with that from photon correlation spectroscopy. MTX-UDLs were uniform in particle size and showed a well-defined inner aqueous phase surrounded by lipid bilayer.

\section{Deformability of MTX-UDLs}

Deformability is a unique characteristic of UDLs, which facilitates the skin permeation across pores smaller than UDLs diameter. The deformation of lipid bilayer induced by an edge activator plays a crucial role in transdermal application of UDLs. The degree of stress-dependent adaptability and shape transformation in UDLs is represented by deformability index. ${ }^{47,48}$ The deformability indices of MTX-UDLs and MTX-CLs are shown in Figure 3. The deformability indices were in the order of MTX-UDLs-T3 (81.2) > MTX-UDLs-S3 (67.8) > MTX-UDLs-T2 (38.9) > MTX-UDLs-S2 (31.6) $>$ MTX-CLs (15.8). There were significant differences $(P<0.01)$ in deformability index between MTX-UDLs and MTX-CLs. The deformability of MTX-UDLs was attributed to the incorporation of SC and TW80 into lipid bilayer instead of $\mathrm{CH}$. From the results, the deformability of MTX-UDLs was affected by the amount and type of the edge activator. MTX-UDLs-T3 and MTX-UDLs-S3 showed better deformability indices than MTX-UDLs-T2 and MTX-UDLs-S2, respectively. As the amount of SC and TW80 increased,
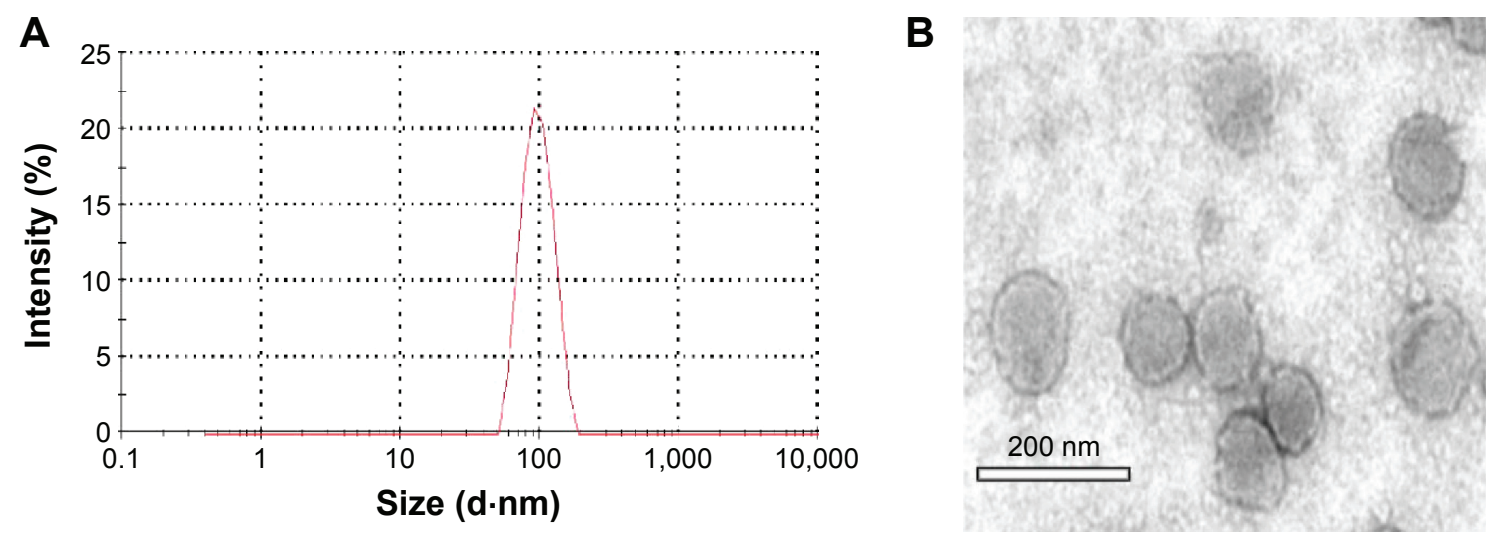

Figure 2 Particle size distribution (A) and TEM image (B) of MTX-UDLs.

Abbreviations: TEM, transmission electron microscopy; MTX-UDLs, methotrexate-entrapped ultradeformable liposomes. 
the deformability index of MTX-UDLs also increased. At a higher amount of edge activator, the deformability of MTX-UDLs did not increase significantly and incorporation efficiency decreased compared with MTX-UDLs-T3 and MTX-UDLs-S3. Moreover, MTX-UDLs with TW80 showed a better deformability index than MTX-UDLs with SC. This could be attributed to the difference in chemical structures between two edge activators. TW80 has long, nonbulky, and highly pliable hydrocarbon chains in the structure, thus providing more flexibility to lipid bilayer, whereas SC has steroidal rings that are less flexible than hydrocarbon chains. ${ }^{27,49}$

\section{In vitro skin permeation of MTX-UDLs}

In vitro skin permeation studies using Franz diffusion cell were performed to evaluate the potential of MTX-UDLs for transdermal delivery. The cumulative amount of MTX permeated at each time point was plotted as a function of time to obtain skin permeation profiles of MTX-UDLs as shown in Figure 4. There were distinct differences between MTX-UDLs and MTX-CLs after 4 hours in the cumulative amount of MTX. From the skin permeation profiles of MTX-UDLs, various skin permeation parameters including the cumulative amount of MTX permeated for 24 hours, steady-state flux $\left(J_{\text {ss }}\right)$, lag time $\left(\mathrm{t}_{\text {lag }}\right)$, permeability coefficient $\left(K_{\mathrm{p}}\right)$, and enhancement ratio were calculated and presented in Table 3. The skin permeation parameters were improved in the order of MTX-UDLs-T3 $>$ MTX-UDLs-S3 $>$ MTXUDLs-T2 > MTX-UDLs-S2 > MTX-CLs > MTX solution.

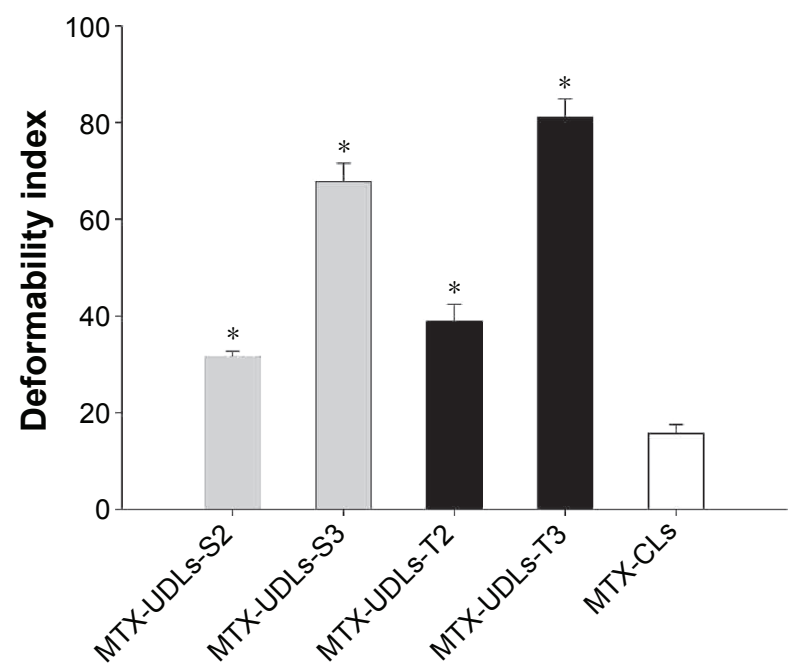

Figure 3 Deformability of MTX-UDLs with different types and amounts of edge activators.

Notes: The deformability of MTX-UDLs was compared with that of MTX-CLs. Data are expressed as mean $\pm S D(n=3)$. $* P<0.0$ l versus MTX-CLs.

Abbreviations: MTX-UDLs, methotrexate-entrapped ultradeformable liposomes; MTX-CLs, methotrexate-entrapped conventional liposomes; SD, standard deviation.

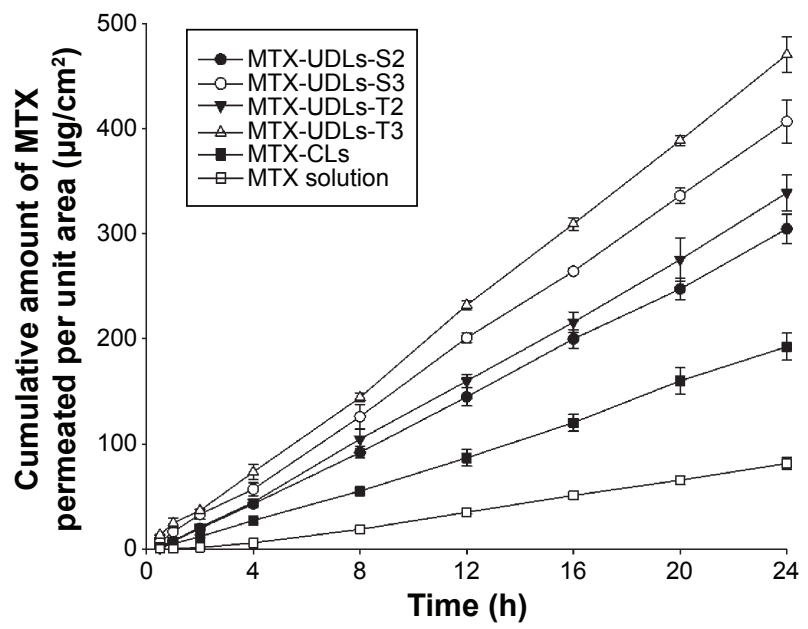

Figure 4 Skin permeation profiles of MTX-UDLs, MTX-CLs, and MTX solution across rat skin for 24 hours.

Note: Data are expressed as mean \pm SD $(n=3)$.

Abbreviations: MTX-UDLs, methotrexate-entrapped ultradeformable liposomes; MTX-CLs, methotrexate-entrapped conventional liposomes; SD, standard deviation; h, hours.

The cumulative amount of MTX permeated, steady-state flux, and permeability coefficient of MTX-UDLs were at least three times greater than those of free MTX solution regardless of the type and ratio of edge activators. From the results, MTX-UDLs were superior to MTX-CLs in all skin permeation parameters $(P<0.01)$. The cumulative amount of MTX permeated for 24 hours and steady-state flux were the highest for MTX-UDLs-T3 at $470.3 \mu \mathrm{g}$ and $20.2 \mu \mathrm{g} / \mathrm{h} / \mathrm{cm}^{2}$, respectively. Accompanied by the increased steady-state flux, permeability coefficient, and enhancement ratio, MTX-UDLs-T3 showed the shortest lag time (0.68 hours), indicating the rapid achievement of steady state in skin permeation. ${ }^{50}$ These findings were in agreement with the results of deformability study. The enhanced skin permeation of MTX-UDLs in comparison to MTX-CLs as a control formulation could be explained by their ability to squeeze themselves through skin pores. The space detentions by skin pores bring about the shape transformation of UDLs, thus enabling them to deliver entrapped drugs across the skin. ${ }^{51}$ The driving force for shape transformation is originated from a transepidermal hydration gradient induced by water content difference between skin surface and epidermis. ${ }^{7,8,52,53}$ The destabilization of intercellular lipids and the increment of membrane fluidity in stratum corneum had been proposed as an alternative mechanism for enhanced skin permeation using UDLs. ${ }^{39,54}$ Considering the low log $P$-value and ionization tendency in physiological conditions, the skin permeation of free MTX via lowered barrier function of stratum corneum by UDLs would be limited. After in vitro 
Table 3 Skin permeation parameters of MTX-UDLs, MTX-CLs, and MTX solution

\begin{tabular}{llllll}
\hline Formulation & $\begin{array}{l}\text { Cumulative amount } \\
\text { permeated for } \mathbf{2 4} \mathbf{~ h}(\mu \mathrm{g})\end{array}$ & $\begin{array}{l}\text { Steady-state flux } \\
\left.\mathbf{(}_{\mathrm{ss}}, \mu \mathrm{g} / \mathbf{c m}^{2} / \mathbf{h}\right)\end{array}$ & $\begin{array}{l}\text { Lag time } \\
\left(\mathbf{t}_{\text {lag }}, \mathbf{h}\right)\end{array}$ & $\begin{array}{l}\text { Permeability } \\
\text { coefficient }\left(\boldsymbol{K}_{\mathrm{p}}, \mathbf{c m} / \mathbf{h}\right)\end{array}$ & $\begin{array}{l}\text { Enhancement } \\
\text { ratio }\end{array}$ \\
\hline MTX-UDLs-S2 & $304.6 \pm 13.9^{*}$ & $13.2 \pm 0.7^{*}$ & $1.02 \pm 0.20^{*}$ & $8.8 \times 10^{-3, *}$ & 1.52 \\
MTX-UDLs-S3 & $406.5 \pm 20.2^{*}$ & $17.4 \pm 0.4^{*}$ & $0.71 \pm 0.18^{*}$ & $11.6 \times 10^{-3, *}$ & 2.01 \\
MTX-UDLs-T2 & $338.8 \pm 17.1^{*}$ & $14.5 \pm 0.9^{*}$ & $0.91 \pm 0.11^{*}$ & $9.7 \times 10^{-3, *}$ & 1.67 \\
MTX-UDLs-T3 & $470.3 \pm 16.8^{*}$ & $20.2 \pm 0.5^{*}$ & $0.68 \pm 0.11^{*}$ & $13.5 \times 10^{-3, *}$ & 2.33 \\
MTX-CLs & $192.4 \pm 13.0$ & $8.7 \pm 0.7$ & $1.86 \pm 0.19$ & $5.8 \times 10^{-3}$ & 1.00 \\
MTX solution & $81.5 \pm 5.7$ & $3.9 \pm 0.4$ & $3.07 \pm 0.48$ & $2.6 \times 10^{-3}$ & 0.45 \\
\hline
\end{tabular}

Notes: Data are expressed as mean $\pm S D(n=3)$. $* P<0.0$ I versus MTX-CLs.

Abbreviations: MTX, methotrexate; UDLs, ultradeformable liposomes; CLs, conventional liposomes; h, hours; SD, standard deviation.

skin permeation studies, the particle size of MTX-UDLs around $100 \mathrm{~nm}$ was detected in the receptor media. There was no structural change of skin after treatments with UDLs, which was confirmed by DSC and FTIR analysis. Therefore, the enhanced skin permeation of MTX-UDLs could be governed mainly by the shape transformation derived from their deformability.

\section{Skin penetration of fluorescence marker (R6G)-entrapped UDLs}

CLSM was conducted to investigate the depth of UDLs skin penetration by monitoring the accumulation of fluorescence marker (R6G). UDLs-T3 with optimal PC to TW80 ratio (7:3, w/w) was selected to entrap R6G for CLSM due to its excellent skin permeation parameters. The rat skin was treated with R6G-UDLs-T3, R6G-CLs, and R6G solution for 4 hours since all the formulations reached the steady state at this time point in skin permeation study. The confocal images of the skin at various depths are illustrated in Figure 5. From the photomicrograph, R6G-UDLs-T3 and R6G-CLs showed a higher fluorescence than R6G solution, specifically from 10 to $40 \mu \mathrm{m}$ skin depth. For the comprehensive and quantitative analysis of R6G penetration, the fluorescence intensity was plotted versus the corresponding skin depth (Figure 6). From the results, the fluorescence intensity of R6G-UDLs-T3 was higher than that of R6GCLs at every increment of skin depth. The maximum fluorescence intensity of R6G-UDLs-T3 was observed as 45.8 AU (arbitrary units) at $20 \mu \mathrm{m}$ skin depth, which was 4.8 and 13.9 times higher than that of R6G-CLs (9.5 AU) and free R6G solution (3.3 AU), respectively. The higher fluorescence intensity of R6G-UDLs-T3 was in accordance with the results from in vitro skin permeation studies. The higher fluorescence intensity of UDLs corresponded to the improved skin permeation since the penetration and accumulation into viable epidermis area are regarded as the processes of percutaneous absorption..$^{34,36}$

\section{Effects of MTX-UDLs on skin structure}

The effects of MTX-UDLs on the lipid organization of stratum corneum were investigated by DSC after treating rat epidermis with MTX-UDLs-T3 for 4 hours. Stratum corneum, flat keratinized corneocytes embedded in intercellular lipid matrix, is regarded as a main permeability barrier in transdermal delivery. Permeation enhancers or transdermal formulations containing alcohols, terpenes, fatty acids, and surfactants penetrate into the intercellular regions and reduce the barrier function of stratum corneum by destabilization and fluidization of lipid bilayers. ${ }^{37,38,55}$ MTX-UDLs-T3 was selected for this study due to its efficient skin permeation among all MTX-UDLs. As shown in Figure 7A, the untreated skin showed endothermic transitions at $65.1^{\circ} \mathrm{C}$, $82.5^{\circ} \mathrm{C}$, and $115.4^{\circ} \mathrm{C}$ for the melting of intercellular lipids, protein-associated lipids, and denatured proteins in stratum corneum, respectively. ${ }^{56}$ When the intercellular lipid bilayer structure of stratum corneum is disrupted, lipid transition temperature around $65^{\circ} \mathrm{C}$ is significantly reduced. ${ }^{57}$ After the treatment with MTX-UDLs-T3, three endothermic transitions at $64.9^{\circ} \mathrm{C}, 82.3^{\circ} \mathrm{C}$, and $115.6^{\circ} \mathrm{C}$ were observed indicating the absence of marked changes in lipid organization. These results suggest that the enhanced skin permeation of MTX-UDLs was not the consequence of structural changes of intercellular lipid layers in stratum corneum.

The lipid organization of stratum corneum was further investigated by ATR-FTIR. FTIR is a reliable technique to give an insight into the molecular organization of lipid matrix by offering bands at different wave numbers. Stratum corneum produces bands at different wave numbers corresponding to lipid and protein molecular vibrations. The peaks of major importance are the asymmetric and symmetric stretching vibrations of $\mathrm{CH}_{2}$ around $2,920 \mathrm{~cm}^{-1}$ and $2,850 \mathrm{~cm}^{-1}$, respectively, derived from the lipid hydrocarbon chains. Moreover, bands around $1,650 \mathrm{~cm}^{-1}$ and $1,550 \mathrm{~cm}^{-1}$ are attributed to the stretching vibrations of amide $\mathrm{I}(\mathrm{C}=\mathrm{O}$ stretching $)$ and amide II bonds ( $\mathrm{C}-\mathrm{N}$ stretching and $\mathrm{N}-\mathrm{H}$ bending) in 

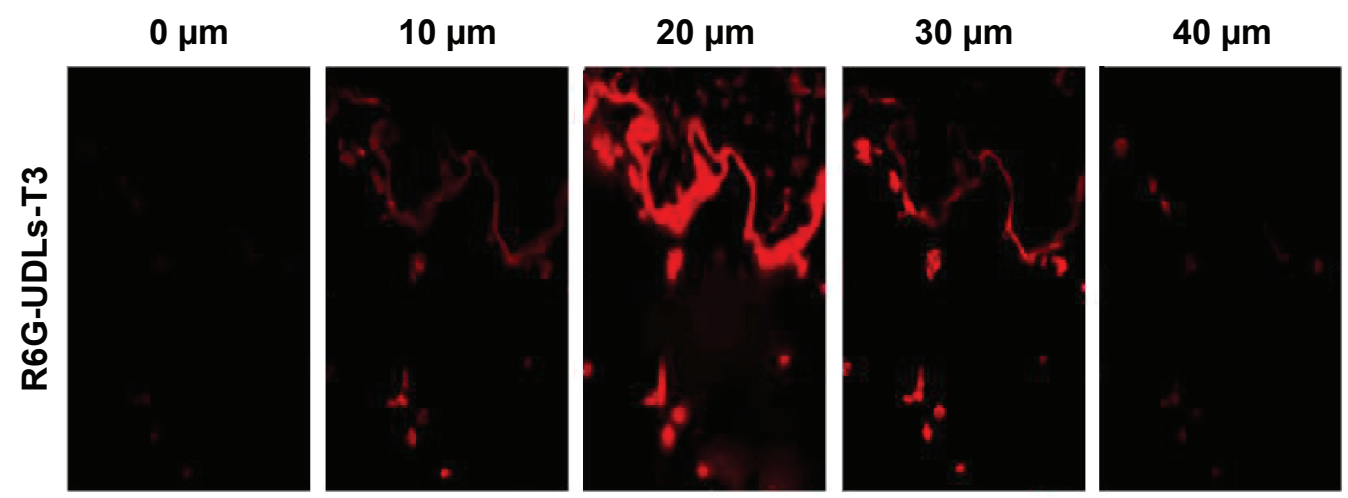

$50 \mu \mathrm{m}$
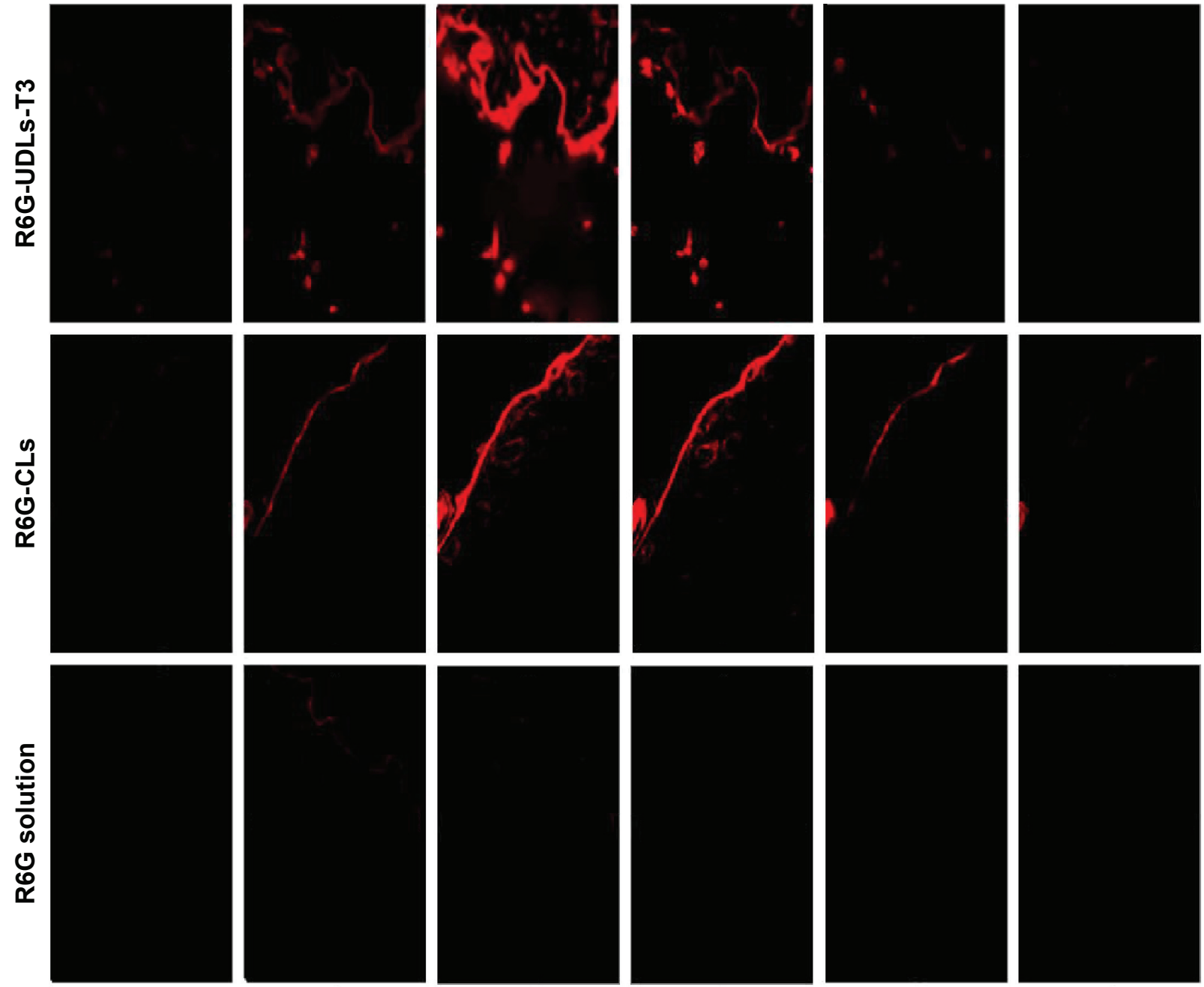

Figure 5 Confocal laser scanning photomicrographs with different depths of rat skin after 4 hour treatments with R6G-UDLs, R6G-CLs, and R6G solution. Abbreviations: R6G, rhodamine 6G; UDLs, ultradeformable liposomes; CLs, conventional liposomes.

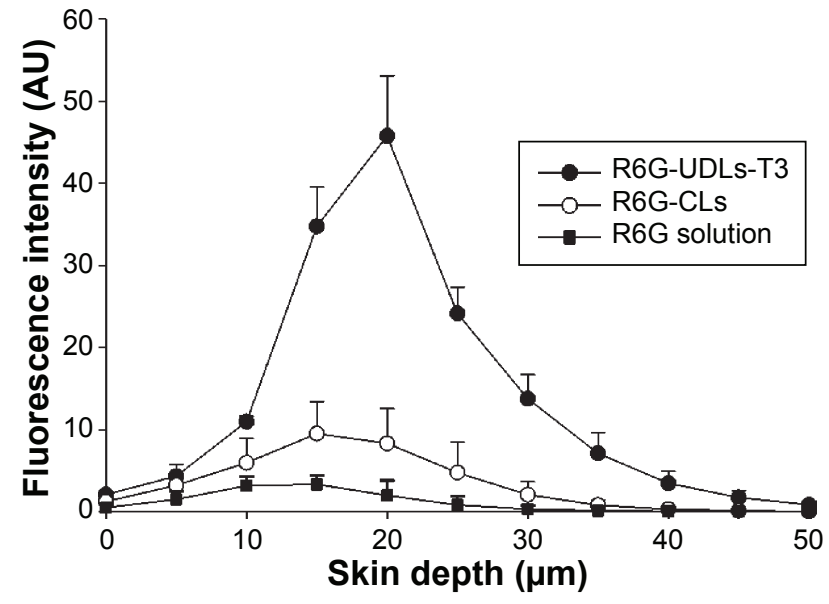

Figure 6 Fluorescent intensity versus skin permeation depth profiles of R6G-UDLsT3, R6G-CLs, and R6G solution.

Note: Data are expressed as mean \pm SD $(n=3)$.

Abbreviations: R6G, rhodamine 6G; UDLs, ultradeformable liposomes; CLs, conventional liposomes; SD, standard deviation. stratum corneum proteins, respectively. ${ }^{37,55}$ The structural changes and fluidization of lipid bilayers in stratum corneum result in a shift of $\mathrm{CH}_{2}$ stretching vibrations to higher wave numbers. ${ }^{55}$ FTIR spectra of the untreated epidermis showed peaks at 2,927.4 $\mathrm{cm}^{-1}, 2,857.9 \mathrm{~cm}^{-1}, 1,639.2 \mathrm{~cm}^{-1}$, and $1,553.4 \mathrm{~cm}^{-1}$, which are assigned to asymmetric stretching vibration of $\mathrm{CH}_{2}$, symmetric stretching vibration of $\mathrm{CH}_{2}$, and stretching vibration of amide I and amide II bonds, respectively (Figure 7B). Furthermore, treatment of the epidermis with MTX-UDLs did not significantly change these vibrations and bands appeared at $2,927.4 \mathrm{~cm}^{-1}, 2,858.5 \mathrm{~cm}^{-1}$, $1,639.2 \mathrm{~cm}^{-1}$, and $1,549.4 \mathrm{~cm}^{-1}$. Taken together, the results of DSC and FTIR suggest that the enhanced permeation of MTX-UDLs is attributed to elasticity and shape transformation ability without severe structural changes in skin. 

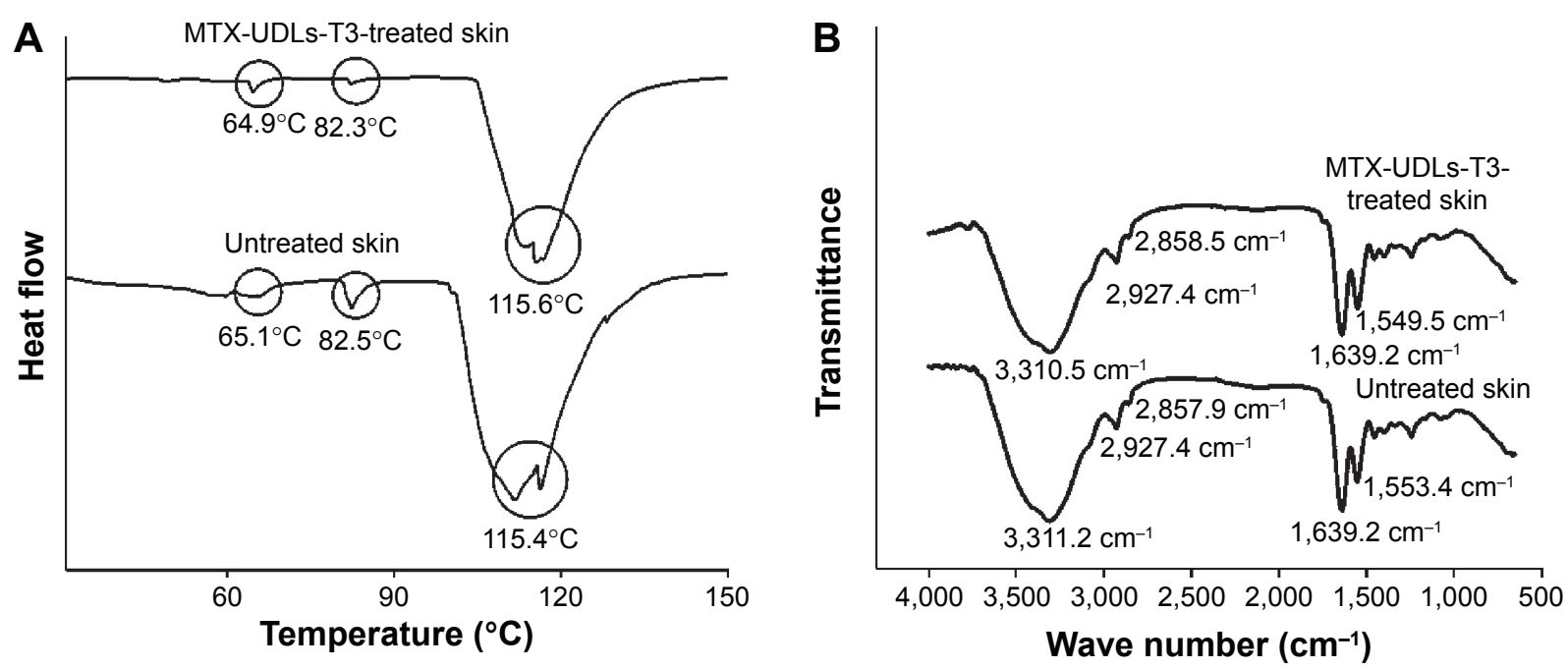

Figure 7 DSC thermograms (A) and FTIR spectra (B) of MTX-UDLs-T3-treated and untreated epidermis from rat skin.

Abbreviations: DSC, differential scanning calorimetry; FTIR, Fourier transform infrared spectroscopy; MTX-UDLs, methotrexate-entrapped ultradeformable liposomes.

\section{Stability of MTX-UDLs}

The stability of the optimized formulation, MTX-UDLs-T3, was evaluated on storage at $4{ }^{\circ} \mathrm{C}$ and $25^{\circ} \mathrm{C}$ for 90 days. MTX-UDLs-T3 was chosen due to its superior skin permeation to all formulations. MTX-UDLs-T3 was evaluated for changes in the physicochemical properties during storage. Lipid vesicular formulations have a natural tendency to fuse, disintegrate, or aggregate during storage, which leads to changes in particle sizes, PDI, and zeta potential. ${ }^{49}$ These changes also bring about drug leakage from the vesicles and reduction in the entrapment efficiency. ${ }^{20}$

MTX-UDLs-T3 moderately maintained its physicochemical properties on storage at $4^{\circ} \mathrm{C}$ for 90 days, while there were marked changes at $25^{\circ} \mathrm{C}$ (Table 4). At $25^{\circ} \mathrm{C}$, the substantial increase in particle size was observed from 87.7 to $158.6 \mathrm{~nm}$ along with a drastic increase in PDI representing heterogeneous particle size distribution. The decrease in zeta potential was also more prominent at $25^{\circ} \mathrm{C}$ than at $4^{\circ} \mathrm{C}$. The particle size growth was accompanied by a decrease in entrapment efficiency of MTX-UDLs-T3 resulting from drug leakage in fusion, disintegration, and aggregation process. A statistically significant drug leakage from MTX-UDLs-T3 at $25^{\circ} \mathrm{C}$ was observed as $25.3 \%$ after 90 days, while only $7.1 \%$ of MTX was lost at $4{ }^{\circ} \mathrm{C}$. Higher temperature not only increases the kinetic energy and collision of the vesicles but also affects the gel-to-liquid transition of lipid bilayers, increasing the chance of lipid degradation and defective membrane packing. ${ }^{58}$ Based on the results, MTX-UDLs have better stability at low temperature compared with room temperature and need to be stored at $4^{\circ} \mathrm{C}$ in aqueous dispersion.

\section{Conclusion}

In this study, MTX-UDLs were prepared by varying the type and ratio of edge activators and were evaluated in terms of physicochemical properties, deformability, and skin permeation. The nanosized homogeneous MTX-UDLs were formed with spherical unilamellar structure. The deformability of MTX-UDLs increased as the amount of the edge activator (TW80 or SC) increased in their composition.

Table 4 Storage stability of MTX-UDLs-T3 at $4^{\circ} \mathrm{C}$ and $25^{\circ} \mathrm{C}$ for 90 days

\begin{tabular}{|c|c|c|c|c|c|c|c|c|c|c|}
\hline \multirow[t]{2}{*}{ Day } & \multicolumn{2}{|c|}{ Size $(n m)$} & \multicolumn{2}{|l|}{ PDI } & \multicolumn{2}{|c|}{ Zeta potential $(\mathrm{mV})$} & \multicolumn{2}{|c|}{$\begin{array}{l}\text { Entrapment } \\
\text { efficiency (\%) }\end{array}$} & \multicolumn{2}{|c|}{ MTX leakage (\%) } \\
\hline & $4^{\circ} \mathrm{C}$ & $25^{\circ} \mathrm{C}$ & $4^{\circ} \mathrm{C}$ & $25^{\circ} \mathrm{C}$ & $4^{\circ} \mathrm{C}$ & $25^{\circ} \mathrm{C}$ & $4^{\circ} \mathrm{C}$ & $25^{\circ} \mathrm{C}$ & $4^{\circ} \mathrm{C}$ & $25^{\circ} \mathrm{C}$ \\
\hline 0 & $87.7 \pm 4.4$ & $87.7 \pm 4.4$ & $0.048 \pm 0.009$ & $0.048 \pm 0.009$ & $-14.7 \pm 1.9$ & $-14.7 \pm 1.9$ & $34.5 \pm 1.4$ & $34.5 \pm 1.4$ & - & - \\
\hline 15 & $91.2 \pm 3.1$ & $98.3 \pm 0.8$ & $0.066 \pm 0.018$ & $0.163 \pm 0.058$ & $-14.5 \pm 0.8$ & $-12.5 \pm 0.9$ & $33.9 \pm 1.2$ & $32.0 \pm 1.3$ & $1.6 \pm 0.2$ & $7.1 \pm 0.2$ \\
\hline 30 & $94.6 \pm 4.3$ & $115.0 \pm 3.8$ & $0.104 \pm 0.020$ & $0.215 \pm 0.056$ & $-14.0 \pm I .4$ & $-11.8 \pm 0.4$ & $33.6 \pm 0.9$ & $30.7 \pm I . I$ & $2.5 \pm 0.2$ & $11.1 \pm 0.2$ \\
\hline 60 & $96.3 \pm 2.8$ & $137.5 \pm 7.2$ & $0.119 \pm 0.024$ & $0.312 \pm 0.130$ & $-13.7 \pm 1.7$ & $-9.5 \pm 1.5$ & $32.7 \pm 1.4$ & $27.7 \pm 1.5$ & $5.3 \pm 0.3$ & $19.7 \pm 0.3$ \\
\hline 90 & $98.6 \pm 1.7$ & $158.6 \pm 9.6$ & $0.132 \pm 0.042$ & $0.342 \pm 0.048$ & $-12.8 \pm 0.7$ & $-8.1 \pm 0.8$ & $32.1 \pm 0.7$ & $25.8 \pm 0.7$ & $7.1 \pm 0.1$ & $25.3 \pm 0.1 *$ \\
\hline
\end{tabular}

Notes: Data are expressed as mean $\pm S D(n=3)$. $* P<0.05$ versus MTX contents at day 0 .

Abbreviations: MTX, methotrexate; UDLs, ultradeformable liposomes; PDI, polydispersity index; SD, standard deviation. 
Skin permeation and deformability of MTX-UDLs were significantly improved compared with those of MTX-CLs. As an edge activator, TW80 was more effective than SC with respect to deformability and skin permeation. The optimized UDLs with TW80 (PC:TW80 =7:3, w/w) were superior to other formulations in MTX delivery across skin. Consequently, MTX-UDLs could be potential nanosized carriers for low-dose MTX treatment of psoriasis and rheumatoid arthritis, while reducing the adverse effects of oral and parenteral administration. In vivo application of the optimized MTX-UDLs to a rheumatoid arthritis rat model is currently under investigation.

\section{Acknowledgment}

This research was supported by Basic Science Research Program through the National Research Foundation of Korea (NRF) funded by the Ministry of Science, ICT \& Future Planning (NRF-2013R1A1A1010181).

\section{Disclosure}

The authors report no conflicts of interest in this work.

\section{References}

1. Barry BW. Novel mechanisms and devices to enable successful transdermal drug delivery. Eur J Pharm Sci. 2001;14(2):101-114.

2. Honeywell-Nguyen PL, Bouwstra JA. Vesicles as a tool for transdermal and dermal delivery. Drug Discov Today Technol. 2005;2(1):67-74.

3. Ranade VV, Cannon JB. Drug Delivery Systems. 3rd ed. Boca Raton, FL: CRC Press; 2011.

4. Barry BW. Dermatological Formulations: Percutaneous Absorption. New York: Marcel Dekker; 1983.

5. Karande P, Mitragotri S. Enhancement of transdermal drug delivery via synergistic action of chemicals. Biochim Biophys Acta. 2009;1788(11): 2362-2373.

6. Elsayed MM, Abdallah OY, Naggar VF, Khalafallah NM. Lipid vesicles for skin delivery of drugs: reviewing three decades of research. Int $J$ Pharm. 2007;332(1-2):1-16.

7. Cevc G, Blume G. Lipid vesicles penetrate into intact skin owing to the transdermal osmotic gradients and hydration force. Biochim Biophys Acta. 1992;1104(1):226-232.

8. Cevc G, Schätzlein A, Richardsen H. Ultradeformable lipid vesicles can penetrate the skin and other semi-permeable barriers unfragmented. Evidence from double label CLSM experiments and direct size measurements. Biochim Biophys Acta. 2002;1564(1):21-30.

9. Cevc G, Blume G. New, highly efficient formulation of diclofenac for the topical, transdermal administration in ultradeformable drug carriers, transfersomes. Biochim Biophys Acta. 2001;1514(2):191-205.

10. Cevc G, Blume G. Biological activity and characteristics of triamcinolone-acetonide formulated with the self-regulating drug carriers, transfersomes ${ }^{\circledR}$. Biochim Biophys Acta. 2003;1614(2):156-164.

11. Cevc G, Blume G. Hydrocortisone and dexamethasone in very deformable drug carriers have increased biological potency, prolonged effect, and reduced therapeutic dosage. Biochim Biophys Acta. 2004; 1663(1-2):61-73.

12. El Maghraby GM, Williams AC, Barry BW. Skin delivery of oestradiol from deformable and traditional liposomes: mechanistic studies. J Pharm Pharmacol. 1999;51(10):1123-1134.
13. El Maghraby GM, Williams AC, Barry BW. Skin delivery of 5-fluorouracil from ultradeformable and standard liposomes in-vitro. J Pharm Pharmacol. 2001;53(8):1069-1077.

14. Cevc G, Gebauer D, Stieber J, Schätzlein A, Blume G. Ultraflexible vesicles, transfersomes, have an extremely low pore penetration resistance and transport therapeutic amounts of insulin across the intact mammalian skin. Biochim Biophys Acta. 1998;1368(2): 201-215.

15. Elsayed MM, Abdallah OY, Naggar VF, Khalafallah NM. Deformable liposomes and ethosomes as carriers for skin delivery of ketotifen. Pharmazie. 2007;62(2):133-137.

16. Ren J, Fang Z, Yao L, et al. A micelle-like structure of poloxamermethotrexate conjugates as nanocarrier for methotrexate delivery. Int J Pharm. 2015;487(1-2):177-186.

17. Choi SJ, Oh JM, Chung HE, Hong SH, Kim IH, Choy JH. In vivo anticancer activity of methotrexate-loaded layered double hydroxide nanoparticles. Curr Pharm Des. 2013;19(41):7196-7202.

18. Stagni G, Shukla C. Pharmacokinetics of methotrexate in rabbit skin and plasma after iv-bolus and iontophoretic administrations. $J$ Control Release. 2003;93(3):283-292.

19. Yang F, Kamiya N, Goto M. Transdermal delivery of the anti-rheumatic agent methotrexate using a solid-in-oil nanocarrier. Eur J Pharm Biopharm. 2012;82(1):158-163.

20. Dubey V, Mishra D, Dutta T, Nahar M, Saraf DK, Jain NK. Dermal and transdermal delivery of an anti-psoriatic agent via ethanolic liposomes. J Control Release. 2007;123(2):148-154.

21. Garg NK, Tyagi RK, Singh B, et al. Nanostructured lipid carrier mediates effective delivery of methotrexate to induce apoptosis of rheumatoid arthritis via NF-KB and FOXO1. Int $J$ Pharm. 2016;499(1-2): 301-320.

22. Pinto MF, Moura CC, Nunes C, Segundo MA, Costa Lima SA, Reis S. A new topical formulation for psoriasis: development of methotrexateloaded nanostructured lipid carriers. Int J Pharm. 2014;477(1-2): 519-526.

23. Chen AZ, Chen LQ, Wang SB, Wang YQ, Zha JZ. Study of magnetic silk fibroin nanoparticles for massage-like transdermal drug delivery. Int J Nanomedicine. 2015;10(1):4639-4651.

24. Nagle A, Goyal AK, Kesarla R, Murthy RR. Efficacy study of vesicular gel containing methotrexate and menthol combination on parakeratotic rat skin model. J Liposome Res. 2011;21(2):134-140.

25. Samah NA, Williams N, Heard CM. Nanogel particulates located within diffusion cell receptor phases following topical application demonstrates uptake into and migration across skin. Int $J$ Pharm. 2010;401(1-2):72-78.

26. Singka GS, Samah NA, Zulfakar MH, Yurdasiper A, Heard CM. Enhanced topical delivery and anti-inflammatory activity of methotrexate from an activated nanogel. Eur J Pharm Biopharm. 2010;76(2): $275-281$.

27. El Zaafarany GM, Awad GA, Holayel SM, Mortada ND. Role of edge activators and surface charge in developing ultradeformable vesicles with enhanced skin delivery. Int J Pharm. 2010;397(1-2): 164-172.

28. Li G, Fan Y, Fan C, et al. Tacrolimus-loaded ethosomes: physicochemical characterization and in vivo evaluation. Eur J Pharm Biopharm. 2012;82(1):49-57.

29. Ruozi B, Belletti D, Tombesi A, et al. AFM, ESEM, TEM, and CLSM in liposomal characterization: a comparative study. Int J Nanomedicine. 2011;6:557-563.

30. van den Bergh BA, Wertz PW, Junginger HE, Bouwstra JA. Elasticity of vesicles assessed by electron spin resonance, electron microscopy and extrusion measurements. Int J Pharm. 2001;217(1-2):13-24.

31. Lv Q, Yu A, Xi Y, et al. Development and evaluation of penciclovirloaded solid lipid nanoparticles for topical delivery. Int J Pharm. 2009; 372(1-2):191-198.

32. El Maghraby GM, Williams AC, Barry BW. Oestradiol skin delivery from ultradeformable liposomes: refinement of surfactant concentration. Int J Pharm. 2000;196(1):63-74. 
33. Zhu W, Yu A, Wang W, Dong R, Wu J, Zhai G. Formulation design of microemulsion for dermal delivery of penciclovir. Int $J$ Pharm. 2008;360(1-2):184-190.

34. Lei M, Wang J, Ma M, Yu M, Tan F, Li N. Dual drug encapsulation in a novel nano-vesicular carrier for the treatment of cutaneous melanoma: characterization and in vitro/in vivo evaluation. $R S C A d v .2015 ; 5(26)$ : 20467-20478.

35. Touitou E, Godin B, Dayan N, Weiss C, Piliponsky A, Levi-Schaffer F. Intracellular delivery mediated by an ethosomal carrier. Biomaterials. 2001;22(22):3053-3059.

36. Wang J, Guo F, Ma M, Lei M, Tan F, Li N. Nanovesicular system containing tretinoin for dermal targeting delivery and rosacea treatment: a comparison of hexosomes, glycerosomes and ethosomes. RSC Adv. 2014;4(85):45458-45466

37. Obata Y, Utsumi S, Watanabe H, et al. Infrared spectroscopic study of lipid interaction in stratum corneum treated with transdermal absorption enhancers. Int J Pharm. 2010;389(1-2):18-23.

38. Cilurzo F, Vistoli G, Selmin F, et al. An insight into the skin penetration enhancement mechanism of N-methylpyrrolidone. Mol Pharm. 2014; 11(3):1014-1021.

39. Elsayed MM, Abdallah OY, Naggar VF, Khalafallah NM. Deformable liposomes and ethosomes: mechanism of enhanced skin delivery. Int J Pharm. 2006;322(1-2):60-66.

40. Lee EH, Kim A, Oh YK, Kim CK. Effect of edge activators on the formation and transfection efficiency of ultradeformable liposomes. Biomaterials. 2005;26(2):205-210.

41. El Maghraby GM, Williams AC, Barry BW. Skin delivery of oestradiol from lipid vesicles: importance of liposome structure. Int J Pharm. 2000;204(1-2):159-169.

42. Perez AP, Altube MJ, Schilrreff P, et al. Topical amphotericin B in ultradeformable liposomes: formulation, skin penetration study, antifungal and antileishmanial activity in vitro. Colloids Surf B Biointerfaces. 2016;139:190-198.

43. Cevc G. Rational design of new product candidates: the next generation of highly deformable bilayer vesicles for noninvasive, targeted therapy. $J$ Control Release. 2012;160(2):135-146.

44. Tasi LM, Liu DZ, Chen WY. Microcalorimetric investigation of the interaction of polysorbate surfactants with unilamellar phosphatidylcholines liposomes. Colloids Surf A Physicochem Eng Asp. 2003;213(1): $7-14$.

45. Duangjit S, Pamornpathomkul B, Opanasopit P, et al. Role of the charge, carbon chain length, and content of surfactant on the skin penetration of meloxicam-loaded liposomes. Int J Nanomedicine. 2014;9: 2005-2017.
46. Yang T, Cui FD, Choi MK, et al. Enhanced solubility and stability of PEGylated liposomal paclitaxel: in vitro and in vivo evaluation. Int $J$ Pharm. 2007;338(1-2):317-326

47. Oh YK, Kim MY, Shin JY, et al. Skin permeation of retinol in Tween 20-based deformable liposomes: in-vitro evaluation in human skin and keratinocyte models. J Pharm Pharmacol. 2006;58(2):161-166.

48. Kang MJ, Eum JY, Jeong MS, et al. Facilitated skin permeation of oregonin by elastic liposomal formulations and suppression of atopic dermatitis in NC/Nga mice. Biol Pharm Bull. 2010;33(1):100-106

49. Jain S, Jain P, Umamaheshwari R, Jain N. Transfersomes-a novel vesicular carrier for enhanced transdermal delivery: development, characterization, and performance evaluation. Drug Dev Ind Pharm. 2003;29(9): 1013-1026.

50. Dubey V, Mishra D, Asthana A, Jain NK. Transdermal delivery of a pineal hormone: melatonin via elastic liposomes. Biomaterials. 2006;27(18): 3491-3496.

51. Cevc G, Schätzlein A, Blume G. Transdermal drug carriers: basic properties, optimization and transfer efficiency in the case of epicutaneously applied peptides. J Control Release. 1995;36(1-2):3-16.

52. Cevc G, Gebauer D. Hydration-driven transport of deformable lipid vesicles through fine pores and the skin barrier. Biophys J. 2003; 84(2 pt 1):1010-1024

53. Honeywell-Nguyen PL, Arenja S, Bouwstra JA. Skin penetration and mechanisms of action in the delivery of the D2-agonist rotigotine from surfactant-based elastic vesicle formulations. Pharm Res. 2003; 20(10):1619-1625

54. Verma DD, Verma S, Blume G, Fahr A. Liposomes increase skin penetration of entrapped and non-entrapped hydrophilic substances into human skin: a skin penetration and confocal laser scanning microscopy study. Eur J Pharm Biopharm. 2003;55(3):271-277.

55. Vaddi HK, Ho PC, Chan YW, Chan SY. Terpenes in ethanol: haloperidol permeation and partition through human skin and stratum corneum changes. J Control Release. 2002;81(1-2):121-133.

56. Cui LL, Liang YY, Dong FJ, et al. Structure of rat skin after application of electret characterized by DSC. J Phys Conf Ser. 2011;301(1):012027.

57. Dreher F, Walde $P$, Walther $P$, Wehrli E. Interaction of a lecithin microemulsion gel with human stratum corneum and its effect on transdermal transport. J Control Release. 1997;45(2):131-140.

58. Dubey V, Mishra D, Jain NK. Melatonin loaded ethanolic liposomes: physicochemical characterization and enhanced transdermal delivery. Eur J Pharm Biopharm. 2007;67(2):398-405.
International Journal of Nanomedicine

\section{Publish your work in this journal}

The International Journal of Nanomedicine is an international, peerreviewed journal focusing on the application of nanotechnology in diagnostics, therapeutics, and drug delivery systems throughout the biomedical field. This journal is indexed on PubMed Central, MedLine, CAS, SciSearch ${ }^{\circledR}$, Current Contents ${ }^{\circledR} /$ Clinical Medicine,

\section{Dovepress}

Journal Citation Reports/Science Edition, EMBase, Scopus and the Elsevier Bibliographic databases. The manuscript management system is completely online and includes a very quick and fair peer-review system, which is all easy to use. Visit http://www.dovepress.com/ testimonials.php to read real quotes from published authors. 